\title{
Drones armados y el uso de fuerza letal: nuevas tecnologías y retos conocidos*
}

\author{
Armed drones and the use of lethal force: New technologies and known challenges
}

Rachel Simon Rushby

Fecha correspondencia:

Recibido: enero 5 de 2017.

Revisión: enero 19 de 2017.

Aceptado: abril 17 de 2017.

Forma de citar:

Rushby, R. (2017). ). Drones

armados y el uso de fuerza

letal: nuevas tecnologías y retos

conocidos. Rev. CES Derecho., 8(1),

22-47.

Open access

Términos de uso

Licencia creative commons

Etica de publicaciones

Revisión por pares

Gestión por Open Journal System

DOl: http://dx.doi.org/10.21615/

cesder.8.1.2

ISSN: 2145-7719

Sobre el artículo:

${ }^{*}$ LL.B. Solicitor, especialista en derechos humanos y derecho internacional humanitario de la Universidad de Antioquia.

Sobre los autores:

1. Artículo para optar al título

de Especialista en Derechos

Humanos y Derecho Internacional

Humanitario. Asesor Jose Yesid

Carillo.

\section{Comparte}

\section{Resumen}

Este artículo considera en primer lugar la legalidad de drones armados en el derecho internacional. Con respecto al uso de drones armados, que ha aumentado exponencialmente en los últimos 15 años, el marco legal depende del contexto en el que los drones se despliegan.

En conflictos armados las reglas que gobiernan el uso de los drones se encuentran en el derecho internacional humanitario; en caso de que los drones armados sean utilizados para mantener el orden público, será aplicable la legislación nacional pertinente y el derecho internacional de los derechos humanos. En Colombia no se conocen casos de uso de drones armados pero, dada su proliferación global, es probable que esta tecnología fuera usada en un futuro próximo.

Este artículo considera los retos legales presentados por los drones armados, aplicándolos a la situación colombiana.

Palabras Claves: Drones Armados, Artículos 35 y 36 del Protocolo Adicional I a los Convenios de Ginebra, Conflictos Armados, Colombia, Derecho Internacional Humanitario -DIH -, Derecho Internacional de los Derechos Humanos - DIDH-.

\section{Abstract}

The use of armed drones has increased exponentially over the past 15 years; this article considers the legality of armed drones in international law.

The legal framework governing the use of armed drones depends on the context in which they are deployed. In armed conflicts the rules governing their use are found in international humanitarian law, if drones are used for law enforcement their use is governed by relevant domestic and international human rights law. We will explore the compatibility of the use of armed drones with both these legal frameworks.

There are no reported cases of Colombia using armed drones but, given their proliferation globally, it is likely that the technology will be adopted. Regardless of when and whether that happens, this article considers the legal challenges presented by drones and applies them to the situation in Colombia. 
Keywords: Armed Drones, Articles 35 and 36 of Additional Protocol I to the Geneva Conventions, Armed Conflicts, Colombia, International Humanitarian Law, International Human Rigths Law.

\section{Introducción}

El uso de aviones sin tripulación en combate se puede remontar al año 1849, cuando el ejército austriaco los utilizó una flota de globos aerostáticos sin tripulación en un ataque contra Venecia. Durante la segunda guerra mundial, ambas partes en conflicto trataron de desarrollar aviones de combate sin tripulación y en la guerra en Vietnam los 'drones Firebee' fueron usados extensamente por parte de los Estados Unidos. Sin embargo, solo más recientemente, y particularmente desde los años 1990 y 2000, que la rápida evolución en la tecnología de computadoras y control remoto ha permitido a los drones armados convertirse en las armas sofisticadas de hoy.

Este artículo se ocupa únicamente de los drones armados. El término 'drone' se refiere solo a la plataforma dirigida por control remoto. La plataforma puede adaptarse a llevar armas o a otros usos variados. Es importante notar que el uso de drones ciertamente no se limita al campo de batalla o a la seguridad estatal. Entre otros usos, se pueden mencionar: la fotografía aérea, la entrega de medicamentos a zonas remotas ${ }^{1}$, y también hubo intentos de usarlos en el narcotráfico (Berger, 2015). Los estados utilizan con frecuencia drones no armados para vigilancia masiva; gran parte de la frontera entre Estados Unidos y México es patrullada usando drones de vigilancia y sabemos a través de Wikileaks que Colombia estaba usando los 'ScanEagle' drones de vigilancia, suministrados por Estados Unidos, en operaciones contra grupos armados en 2006 (The Global Intelligence Files, 2013).

Cuando hablamos de drones armados estamos considerando el uso de fuerza letal. Mientras hay drones con la capacidad de desplegar una fuerza menor (por ejemplo, pistolas paralizantes), hay pocos reportes, o ninguno, del uso de éstos. El uso más reportado de drones armados es de los Estados Unidos como parte del 'war on terror' conducido por esta nación desde el 2001. Pero no son solo los Estados Unidos quienes tienen acceso a esta tecnología; países tan diversos como Nigeria y Emiratos Árabes Unidos tienen drones armados y también grupos no estatales como Hezbollah y Hamas (Hezbollah afirma tener la capacidad de fabricar drones armados, sin embargo, aun la veracidad de esta declaración no es cierta) (Sims, 2016) ${ }^{2}$.

Recientemente ISIS ha utilizado un dron armado básico en un ataque contra fuerzas kurdas en el norte del Irak. La proliferación de drones armados es alimentada por países como China e Irán, que tienen capacidad de producirlos y la voluntad de suministrarlos sin restricciones legales (como el Tratado Sobre el Comercio de Armas). La proliferación de drones es un tema significativo cuando consideramos la probabilidad de que Colombia o grupos armados en Colombia obtengan esta tecnología en un futuro cercano.

Este artículo trata de explorar los desafíos legales planteados por la creciente disponibilidad y uso de drones armados con especial atención a Colombia. En primer lugar evaluamos la legalidad de drones como armamentos bajo el derecho internacional. A continuación, examinamos la legalidad del uso de drones armados. En este contexto es necesario establecer si se despliegan en un conflicto armado o para

1 Para consultar un ejemplo véase: http://www.dronesfordevelopment.com/

2 Para datos sobre el uso y acceso a drones véase http://securitydata.newamerica.net/world-drones.html 
finalidades de orden público, porque esta distinción determina el marco jurídico en el que el tema de la legalidad debería ser juzgado.

En el contexto de un conflicto armado el uso de drones está gobernado por el derecho internacional humanitario (DIH). Aquí consideramos la definición de "conflicto armado" y los retos que los conflictos modernos plantean a esta definición tradicional. Los drones son capaces de cruzar fronteras internacionales de manera oculta; operadores basados en centros de control desde miles de kilómetros de distancia pueden apuntar a individuos en lugares donde el estado operativo no tiene control ni presencia territorial. Utilizados de esta manera los drones representan un reto significativo para el Derecho Internacional Humanitario -DIH-. Se considera en detalle el uso de drones por parte de los Estados Unidos porque es el más reportado internacionalmente y ejemplifica muchos de los desafíos.

La idea de drones armados utilizados para garantizar el orden público quizás es un modelo más futurístico. Este uso sería gobernado por el derecho internacional de los derechos humanos (DIDH), cuyas reglas constituyen un marco legal más restrictivo para el uso de fuerza letal. La distinción entre los paradigmas de conflicto armado y orden público es difícil de establecer. Analizamos las reglas del Derecho Internacional de los Derechos Humanos - DIDH- porque se aplican cada vez que un Estado despliega drones armados (fuerza letal) por fuera de una situación de conflicto armado.

Mientras no es claro si Colombia tiene disponibilidad de drones armados, muchos de los retos legales presentados por el uso de drones armados en otros países son relevantes a la situación Colombiana. Este artículo intenta explorar los asuntos legales y las lecciones para aprender en tema de uso de drones armados en el mundo.

\section{La Legalidad de los drones armados}

El uso y disponibilidad de drones armados ha aumentado exponencialmente desde los ataques contra los Estados Unidos del 11 de septiembre de 2001. Se puede ver este fenómeno como consecuencia del desarrollo tecnológico y el carácter evolutivo de los conflictos armados. La capacidad de grupos armados de montar ataques, no solo a través de fronteras, pero desde continentes diferentes, ha hecho de los drones las armas de elección en el combate de estos grupos. El uso de drones ha dado lugar a algunos críticos, muchos de los cuales objetan no solo la manera en la cual los drones son usados, sino también su mera existencia y uso como armamentos.

Cuando consideramos la legalidad de drones per se es útil tener en cuenta el contexto histórico. El ideal del 'guerrero heroico' está profundamente radicado en nuestra sociedad y muchas de nuestras reacciones a una guerra asimétrica (de la cual los drones quizás son el epítome) derivan de este ideal cultural, ampliamente compartido pero casi sin duda obsoleto. Nuevas tecnologías de armas inevitablemente presentan nuevos dilemas éticos, como en el siglo XVI cuando las flechas se consideraban un arma de destrucción masiva; el reto es tratar de solucionar estos dilemas de la manera más objetiva posible.

No hay tratados ni derecho consuetudinario que prohíban el uso de drones armados per se. En el DIH convencional las reglas sobre los medios de guerra están contenidas principalmente en los artículos 35 y 36 del Protocolo I adicional de 1977 (Protocolo I) a los cuatro Convenios de Ginebra del 1949, relativo a la protección de las víctimas de los conflictos armados internacionales. Mientras el Protocolo I se 
aplica solo a los conflictos armados internacionales, las reglas consagradas en los artículos 35 y 36 forman parte del derecho internacional consuetudinario y por eso se aplican igualmente a ambos conflictos, internacionales y no internacionales. Adicionalmente, los armamentos tienen que ser capaces de cumplir con los principios del DIH, es decir, distinción, precaución y proporcionalidad.

Nos concentramos aquí en los artículos 35 y 36, y los principios del DIH que serán considerados en mayor detalle más adelante.

El artículo 35 afirma: "En todo conflicto armado, el derecho de las partes en conflicto a elegir los métodos o medios de hacer la guerra no es ilimitado" (Artículo 35, numeral 1) y prohíbe el empleo de armas que causan "males superfluos o sufrimientos innecesarios" (Artículo 35, numeral 2). Los drones son plataformas dirigidas por un control remoto que pueden ser utilizados para portar armas de proyectiles.

Es posible que un dron pueda ser usado con una arma (proyectil) prohibida, como armas químicas o municiones en racimo, y en este caso es cierto que su uso sería prohibido. Sin embargo, si consideramos los drones -que son fabricados actualmente- no hay evidencia que estos causan males superfluos o sufrimientos innecesarios. Los drones tienen la capacidad de lanzar municiones ligeras y se ha sugerido que la dispersión de la metralla de las municiones desplegadas de los drones es menos que de una bomba lanzada por un avión convencional (Grzebyk, 2015).

Mientras que en principio los drones deberían ser armamentos más precisos, su uso es frecuentemente velado en confidencialidad y por eso es difícil de analizar si en la práctica es así. El artículo 36 dice:

Cuando una Alta Parte Contratante estudie, desarrolle, adquiera o adopte una nueva arma, o nuevos medios o métodos de guerra, tendrá la obligación de determinar si su empleo, en ciertas condiciones o en todas las circunstancias, estaría prohibido por el presente Protocolo o por cualquier otra norma de derecho internacional aplicable a esa Alta Parte Contratante.

Muchas veces los ataques con drones ocurren en zonas remotas donde la fuerza militar no tiene presencia sobre el terreno y las cuentas de víctimas vienen únicamente de la prensa local o líderes comunitarios que pueden tener motivos para exagerar o minimizar las víctimas. Después de mucha presión internacional los Estados Unidos finalmente han publicado en julio de 2016 su registro sobre las víctimas civiles durante su programa de uso de drones en el Medio Oriente de los últimos seis años ${ }^{3}$. Las cifras reconocen pocas víctimas civiles pero los críticos dicen que éstas no son confiables, y dependen de a quien el gobierno clasifique como 'combatiente' (por ejemplo el supuesto que todo los hombres en edad militar son 'combatientes') (Byman, 2013) (Zenko, 2016). Otros informes de organizaciones no gubernamentales - ONGs-y sociedad civil siguen ubicando las cifras de las víctimas civiles mucho más altas (algunos llegan a 1 de cada 3 ). La falta de datos fiables sobre la eficacia de drones armados hace difícil que un estado cumpla con los requisitos del artículo 36 y han conducido a algunos a argumentar que los estados están obligados a publicar datos fiables sobre sus ataques con drones para poder evaluar su legalidad (McNeal, 2012).

Dejando aparte los argumentos sobre la rendición de cuentas y la compatibilidad con El artículo 36, parece que, como lo dice el Relator Especial de la ONU Philip Alston: 
Un misil lanzado de un dron no es diferente de cualquier otro armamento utilizado comúnmente, incluyendo una pistola disparada por un soldado o un helicóptero de combate que lanza un misil. La pregunta critica es la misma para cada armamento: si su uso específico cumple con el DIH (Alston, 2010).

\section{Los usos de drones}

La capacidad de que los drones puedan usar fuerza que no sea letal o de capturar sospechosos sigue siendo limitada o, en este último caso, inexistente. Reconociendo que, en un mundo de rápido avance tecnológico, esto está destinado a cambiar en un futuro no muy lejano, este artículo se centra en la legalidad de una fuerza letal desplegada por drones armados.

Como hemos dicho anteriormente, el punto de partida cuando tratamos de determinar la legalidad de un ataque con drones armados y el uso de fuerza letal, es establecer el contexto en el cual el dron se despliega, por ejemplo, si se usa durante un conflicto armado, por 'legítima defensa' bajo el derecho internacional, o como una medida policial. Esta distinción es importante porque, mientras el DIDH sigue siendo vinculante durante conflictos armados, el uso de fuerza letal ocupa una posición de lex specialis en la cual el marco legal es lo del más permisivo DIH.

\section{Conflictos Armados}

La existencia de un conflicto armado se determina en base a los hechos de cada caso. Dependiendo de si un conflicto es internacional o no internacional, aplican marcos legales distintos, entonces no solo hay que determinar si hay conflicto armado sino también operar una clasificación del conflicto. Esta determinación depende en gran parte de las partes en conflicto. En teoría puede parecer fácil definir el tipo de conflicto, pero en la práctica muchas veces la distinción es complicada, especialmente cuando, como es cada vez más común, conflictos no internacionales cruzan fronteras internacionales.

\section{Conflictos armados internacionales}

En conflictos armados internacionales, normalmente la determinación de si existe un conflicto armado es cosa fácil. Cualquier uso de fuerza entre dos o más estados es considerado un conflicto armado internacional para los fines del $\mathrm{DIH}^{4}$. En otras palabras, "cualquier uso de fuerza armada contra el territorio de otro [estado], desencadena la aplicabilidad de los Convenios de Ginebra entre los dos estados... Tampoco importa si la parte bajo ataque resista o no" (Gasser, 1993) ${ }^{5}$. La intensidad de la violencia no es relevante, ni el reconocimiento de la existencia de un conflicto armado por los estados involucrados. Esto puede ser derivado del articulo común 2 a los cuatro Convenios de Ginebra, que también amplía la aplicación de los Convenios a "todos los casos de ocupación total o parcial del territorio de una Alta Parte Contratante, aunque tal ocupación no encuentre resistencia militar". El artículo 1(4) amplía aún más esta definición a, "los conflictos armados en que los pueblos luchan contra la dominación colonial y la ocupación extranjera y contra regímenes racistas, en el ejercicio del derecho de los pueblos a la libre determinación".

Jus ad Bello

La regla general que prohíbe el uso de fuerza armada por un estado en el territorio de otro estado es contenida en el artículo 2(4) de la Carta de las Naciones Unidas (la

4 En el caso Tadic se dice, "an armed conflict occurs whenever there is a resort to armed force between States" Decision on the Defence Motion for Interlocutory Appeal on Jurisdiction, IT-94-1-A. Octubre 2,1995, párrafo 70

5 Cotizado en "How is the Term "Armed Conflict" Defined in International Humanitarian Law", ICRC Opinion Paper (Marzo 2008) 
Carta) que dice, "Los Miembros de la Organización, en sus relaciones internacionales, se abstendrán de recurrir a la amenaza o al uso de la fuerza contra la integridad territorial o la independencia política de cualquier Estado, o en cualquier otra forma incompatible con los Propósitos de las Naciones Unidas" ${ }^{\prime}$. Prima facie, un ataque con un dron armado por un estado en el territorio de otro viola el artículo 2(4).

\section{Hay tres excepciones generales a esta prohibición del uso de fuerza:}

Según el artículo 42 de la Carta, el Consejo de Seguridad tiene el poder de autorizar el uso de fuerza "que sea necesaria para mantener o restablecer la paz y la seguridad internacionales".

Cuando un estado da su consentimiento al uso de fuerza, este uso no afecta la soberanía y el artículo 2(4) no tiene relevancia.

El artículo 51 de la Carta permite a los estados usar fuerza en su 'legítima defensa'.

La administración Obama se ha alejado de la idea de 'guerra global contra el terrorismo' o 'doctrina Bush', en cambio afirmando que cuando se usan drones armados esto sea con el consentimiento del estado anfitrión o por legítima defensa. Estas son las dos excepciones más relevantes cuando consideramos la legalidad del uso de drones y por esto las examinamos en más detalle aquí.

\section{Consentimiento}

Está bien establecido que cuando un Estado solicita la intervención, o da su consentimiento a la misma, de otro estado, no hay una violación de soberanía o integridad territorial7. Por tanto, si el Estado A tiene un conflicto armado interno y, con el consentimiento del Estado A, el Estado B interviene en el conflicto, esta intervención no afecta la clasificación del conflicto, que sigue siendo de carácter no internacional. Igualmente, si el conflicto desde el Estado A se derrama en el Estado $\mathrm{C}$ y este último da su consentimiento al accionar militar del Estado A en su territorio, el conflicto continúa siendo de naturaleza no internacional (la integridad territorial del Estado C no ha sido violada porque el Estado $C$ consintió las acciones del Estado A). Sin embargo, un estado no puede consentir violaciones de los DIH o DIDH y los estados siguen sujetos a sus obligaciones bajo el derecho internacional.

Vale la pena notar que no es siempre fácil determinar si un estado ha dado su consentimiento a la intervención militar por un segundo estado. El ejemplo más obvio a este respecto son los ataques con drones conducidos por los Estados Unidos en el territorio de Pakistán. El Primer Ministro pakistaní Gilani supuestamente había dicho lo siguiente en agosto de 2008 con respeto a ataques con drones en la región del Khyber Pakhtunkhwa: "No me importa si lo hacen mientras encuentran las personas correctas. Protestaremos en la asamblea nacional y después lo ignoraremos" (El Caso de Asesinatos Selectivos en Pakistan). Parece que, a pesar de sus protestas públicas, Pakistán ha consentido a la mayoría de los ataques con drones conducidos en su territorio por los Estados Unidos ${ }^{8}$

6 Una disposición similar se encuentra en el artículo 21 de la Carta de las Organización de los Estados Americanos: "El territorio de un Estado es inviolable; no puede ser objeto de ocupación militar ni de otras medidas de fuerza tomadas por otro Estado, directa o indirectamente, cualquiera que fuere el motivo, aun de manera temporal. No se reconocerán las adquisiciones territoriales o las ventajas especiales que se obtengan por la fuerza o por cualquier otro medio de coacción".

7 Véase por ejemplo, Military and Paramilitary Activities in and against Nicaragua (Nicaragua v. United States of America). Merits, Judgment. I.C.J. Reports 1986, p. 14.

8 Por un discusión más detallado sobre esto punto se refiere al informe del New York City Bar Committee on International Law, "The Legality Under International Law of Targeted Killings by Drones Launched by the United States" (Junio 2014) 


\section{Legítima Defensa}

El artículo 51 de la Carta dice lo siguiente, "Ninguna disposición de esta Carta menoscabará el derecho inmanente de legítima defensa, individual o colectiva, en caso de ataque armado contra un Miembro de las Naciones Unidas, hasta tanto que el Consejo de Seguridad haya tomado las medidas necesarias para mantener la paz y la seguridad internacionales. Las medidas tomadas por los Miembros en ejercicio del derecho de legítima defensa serán comunicadas inmediatamente al Consejo de Seguridad, y no afectarán en manera alguna la autoridad y responsabilidad del Consejo conforme a la presente Carta para ejercer en cualquier momento la acción que estime necesaria con el fin de mantener o restablecer la paz y la seguridad internacionales".

Este artículo es problemático y es difícil de encontrar un acuerdo académico sobre los parámetros de su aplicación pero, dado que los usuarios más prolíficos de drones armados frecuentemente justifican sus acciones como 'defensa legítima', es importante tratar de entender el concepto.

Bajo la Carta, los estados pueden invocar su derecho de legítima defensa solo en caso de un ataque armado. ¿Pero qué es un 'ataque armado'? En los Principios de Chatham House, un ataque armado es definido como "una intervención intencional dentro de o contra otro estado sin el consentimiento de este estado ni su posterior aquiescencia y que no tenga justificación legal"; y además se afirma en los Principios que un "ataque armado significa cualquier uso de fuerza, sin que sea necesario superar un determinado grado de intensidad" (Chatham House). Sin embargo, como ha observado el académico David Kretzmer, hay una diferencia de lenguaje entre los artículos 2(4) y 51. El artículo 2(4) prohíbe cualquier uso de fuerza, mientras el artículo 51 se refiere a un "ataque armado" (Kretzmer, 2013). La sugerencia es que la intención de la Carta era de prohibir cualquier uso de fuerza entre estados y que solo un 'ataque armado' (implicando un mayor grado de fuerza) pueda justificar una excepción a esta prohibición general. La jurisprudencia de la Corte Internacional de Justicia $(\mathrm{ClJ})$ respalda esta opinión, como consistentemente ha dicho que solo los ataques más graves pueden representar 'ataques armados' y ha tratado de hacer una distinción entre 'ataques armados' y meros incidentes fronterizos ${ }^{9}$. Se sugiere en este artículo que la interpretación correcta es que hay que cruzar un determinado grado de violencia para que un incidente se pueda calificar como un 'ataque armado'. Los Principios de Chatham House sugieren que, si un incidente es de naturaleza mínima esto formaría una parte de la consideración de si sea necesario actuar en legítima defensa. Dado que el propósito de la Carta es el mantenimiento de la paz y seguridad internacionales, se sugiere que los autores de la Carta probablemente no quisieron dejar una discreción tan amplia para los estados en elegir si el uso de fuerza en legítima defensa sea justificado.

Si aceptamos que hay un umbral de violencia que se tiene que superar antes que un ataque pueda ser considerado un 'ataque armado', hay que considerar si una serie de ataques menores puedan formar un ataque armado, 'teoría de acumulación de eventos'. A pesar que esta teoría sea adoptada por estados como Estados Unidos e Israel, no hay consenso si es legalmente válida. Sin embargo, como la naturaleza del terrorismo ha cambiado y sigue cambiando, parece que esta teoría está logrando un reconocimiento siempre más amplio.

9 En el caso de Nicaragua, la ClJ afirmó que un ataque armado tiene que contener las formas de violencia más grave para que una legítima defensa sea justificada bajo el articulo 51 
La opinión mayoritaria es que un 'ataque armado' no tiene que emanar de o ser imputable a un estado enemigo. Tanto la jurisprudencia de la Corte Internacional de Justicia - ClJ- como las resoluciones del Consejo de Seguridad (en particular las adoptadas después de los ataques en setiembre 1110) apoyan la noción que un 'ataque armado' pueda emanar da un grupo armado no estatal. Una limitación es la afirmada por la $\mathrm{ClJ}$ en al caso de Nicaragua, que un grupo no estatal tiene que ser capaz de montar un ataque, "de tal gravedad que sea (inter alia) equiparable a un ataque armado realizado por las fuerzas regulares" (Military and Paramilitary Activities in and against Nicaragua, 1986). Si abandonamos el concepto de un 'ataque armado' como un ataque grave o en gran escala, y aceptamos que dicho ataque pueda emanar de un grupo no estatal y sin vínculos con el estado anfitrión, hay el peligro que la legítima defensa pueda empezar a parecerse a la acción policial. ${ }^{11}$

El artículo 51 solo permite a un estado de usar fuerza en caso de que se haya producido un 'ataque armado', por lo tanto, se plantea la pregunta si un estado pueda usar fuerza en legítima defensa antes de un ataque, en otras palabras, 'legítima defensa anticipada'. Esta es una pregunta que podemos contestar con relativa facilidad: en general se acepta que la legítima defensa anticipada está permitida en el derecho internacional. El derecho internacional consuetudinario de legítima defensa se origina en el incidente de Caroline. Caroline era el nombre de un buque americano que fue destruido por la armada británica mientras se acercaba a la isla 'Navy', ubicada en aguas canadienses, en 1837. En aquella época la isla era dominio colonial de los británicos y rebeldes contra el gobierno colonial estaban recibiendo asistencia de simpatizantes americanos. El buque 'Caroline' estaba llevando suministros a los rebeles y los británicos justificaron la destrucción del buque como legítima defensa anticipada.

Las reglas que gobiernan la legítima defensa anticipada en el derecho internacional consuetudinario se derivan de la correspondencia entre el secretario de estado estadounidense y el embajador británico que siguió al incidente. La noción que la necesidad de legítima defensa debe ser instantáneo, abrumador y que no se deje otras opciones de medidas ni momentos por deliberación, se convirtió en la norma por la determinación de cuándo la legítima defensa anticipada fuese justificada. Muchos comentadores creen que el artículo 51 preserva este derecho consuetudinario a través de la afirmación: "Ninguna disposición de esta Carta menoscabará el derecho inmanente de legítima defensa, individual o colectiva..." La práctica estatal desde la Carta ha confirmado el derecho a usar legítima defensa anticipada.

El derecho internacional consuetudinario requiere que, en el ejercicio de legítima defensa, los estados cumplan con los principios de proporcionalidad y necesidad (Opinión Consultiva de la Corte Internacional de Justicia sobre la Legalidad de la Amenaza o Empleo de Armas Nucleares, 1996). Adicionalmente, cuando un estado actúa en legítima defensa anticipada se requiere la condición de inminencia, como la definida en el caso Caroline.

Necesidad en este contexto puede ser interpretada en el sentido que no haya ninguna alternativa viable disponible al estado que ejerce su derecho de legítima defensa, excepto el uso de fuerza. En situaciones en las cuales la amenaza proviene de un grupo armado no estatal, cabe preguntarse si el estado defensor debería buscar la cooperación del estado anfitrión antes de recurrir al uso de fuerza en su territorio.

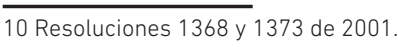

11 Quizás eso sea particularmente pertinente cuando el estado que ejerce el derecho a legítima defensa hace lo contra personas individuas (al contrario de sitios usados por el grupo armado) 
Es probable que el requisito de necesidad solo se pueda considerar cumplido si el estado anfitrión no quiere o no puede actuar contra la amenaza y de esto se deduce que, en la mayoría de los casos, el estado defensor debería solicitar el consentimiento o cooperación del estado anfitrión antes de llevar a cabo ofensivas militares en su territorio. Hay situaciones previsibles en las que el estado defensor no quiera compartir información sensible con el estado anfitrión. En estas situaciones, si el estado defensor lleva a cabo operaciones sin obtener el previo consentimiento o cooperación, se sugiere determinar sobre la base de los hechos del caso si sus acciones fuesen necesarias.

La ausencia de consentimiento/cooperación no cumple por sí sola el requisito de necesidad; el estado defensor todavía necesita considerar las circunstancias para decidir si la acción propuesta es necesaria. Se sugiere aquí que, cuando no hay el consentimiento del estado anfitrión, la violación de la soberanía que sigue inevitablemente al uso de fuerza por parte del estado defensor en el territorio del estado anfitrión, debería poner un listón alto por los estados cuando consideran si sus acciones propuestas son proporcionales (al respecto véase más adelante).

Si el estado defensor decide llevar un ataque en el territorio del estado anfitrión sin el consentimiento de este último, el derecho del conflicto armado internacional será aplicable, en cuanto no solo será un ataque contra el grupo armado, sino también contra la integridad territorial del estado anfitrión.

El asunto de proporcionalidad en legítima defensa es complejo. A diferencia de jus in bello, no hay una definición aceptada del concepto de proporcionalidad en jus ad bello. El término 'proporcionalidad' tiene varias interpretaciones dependiendo del contexto. En jus in bello proporcionalidad es el ejercicio de sopesamiento: ¿es el daño incidental justificado, dada la legítima ventaja militar prevista? (Artículo 51, numeral 5 del Protocolo Adicional I).

En la práctica puede ser muy difícil de aplicar pero, al menos en teoría, el test es claro. En contraste, cuando consideramos el jus ad bello, el significado de proporcionalidad no es claro; ¿significa proporcional al ataque armado original, un enfoque 'ojo por ojo', o proporcional al objetivo de proteger el estado defensor? Mientras que no hay consenso, la opinión de la mayoría favorece la última interpretación, que Kretzmer describe como un 'medios-fin' test de proporcionalidad (Kretzmer, 2013).

Pero aun esta interpretación deja preguntas sin respuestas, que no hay espacio aquí para explorar. Sin embargo, debería notarse que esta ausencia de claridad crea problemas cuando consideramos el uso de drones por parte de los Estados Unidos e Israel para responder a una cadena de ataques. ¿Si la teoría de la acumulación de eventos ha sido usada para justificar el uso de fuerza por legítima defensa, está autorizado el estado defensor a eliminar el riesgo de futuros ataques? (¿y si la respuesta es afirmativa, cuando es el riesgo demasiado remoto?) o ¿sólo puede detener y repeler una amenaza inmediata parte de la cadena? La segunda interpretación limitaría la capacidad del estado defensor a usar la fuerza solo en situaciones en que tenga información de un ataque específico, mientras la primera interpretación daría poderes más amplios, de atacar el enemigo solo porque es el enemigo.

El requisito final es la inminencia. Esta es vinculada intrínsecamente al requisito de necesidad y en su informe, "The Legality under International Law of Targeted Killings by Drones Launched by the United States", el comité del New York City Bar, concluye 
que en realidad la inminencia no es un criterio independiente sino que forma una parte del requisito de necesidad. Se sugiere que el mejor abordaje sea lo adoptado en los Chatham House Principles, donde se afirma que la existencia de la inminencia como un criterio independiente sirve para enfatizar, "que una repuesta forzosa en estas circunstancias se radica al límite de una categoría legal que ya es excepcional, y por eso requiere un nivel de justificación correspondientemente alto" (Chatham House). La inminencia sugiere que el estado defensor no tenga tiempo para buscar efectivamente medidas no forzosas, que algo sea 'instantáneo y abrumador' y que 'no se deje ningún momento para deliberación', como se ha afirmado en el caso de Caroline, en otras palabras, el "elemento temporal es la creencia que más demora hará el estado defensor incapaz de defenderse" (Chatham House).

El elemento temporal de la inminencia ha sido socavado por los Estados Unidos en su aplicación de la doctrina de legítima defensa en su uso de drones, con el resultado de amplificar la interpretación de inminencia. En un discurso en 2011 John Brennan afirmó: "el concepto tradicional de lo que constituye un ataque inminente debería ser ampliado en luz de capacidades modernas, técnicas e innovaciones tecnológicos de organizaciones terroristas" (John Brennan, 2016) ${ }^{12}$. Es decir, se aplica una noción de inminencia que desafía el entendimiento común de la palabra y que no requiere inmediatez.

La evaluación de los criterios de legítima defensa es subjetiva. Sin embargo, es importante que los estados actúen en buena fe y tomen decisiones basadas en hechos objetivos. En la mayoría de los casos, la legalidad de las acciones de un estado se juzgará después de los hechos y por lo tanto debe haber transparencia y rendición de cuentas en el proceso decisional. Por último, se debería recordar que el artículo 51 sugiere que la legítima defensa sea una medida temporal, "hasta tanto que el Consejo de Seguridad haya tomado las medidas necesarias para mantener la paz y la seguridad internacionales".

\section{Conflictos armados no internacionales}

En casos de conflictos armados internos o no internacionales, determinar si hay un conflicto armado o simplemente, "situaciones de tensiones internas y disturbios interiores, tales como los motines, los actos esporádicos y aislados de violencia" es tema más complejo (Artículo I, Protocolo Adicional II). Para una orientación se puede consultar la jurisprudencia de la Corte Penal Internacional y de tribunales ad hoc. En Prosecutor v Tadic, el Tribunal Penal Internacional para la ex Yugoslavia (TPIY) dijo: "existe un conflicto armado cada vez que se recurre a la fuerza armada entre Estados o hay violencia armada prolongado entre autoridades gubernamentales y grupos armados organizados o entre tales grupos en el seno de un Estado"13. En Prosecutor v. Boskoski, el TPIY identificó dos criterios para juzgar si existe un conflicto armado: "(i) la intensidad del conflicto y (ii) la organización de las partes en conflicto"14. Lo que está claro es que hay un umbral de violencia que debe ser pasado antes de que una situación pueda ser considerada un conflicto armado. Este umbral es una importante garantía que debería prevenir que los estados usen el DIH para legitimar el uso de fuerza letal en situaciones de menor violencia. En las situaciones que no califican como conflictos armados el más restrictivo DIDH va a aplicar (véase más adelante).

12 Citado en Steven J. Barela, "The Question of "Imminence: A Historical View on Anticipatory Attacks".

13 Prosecutor v. Dusko Tadic, Decisión sobre la moción de apelación interlocutoria sobre jurisdicción, IT-94-1-A, 2 October 1995, para. 70.

14 Prosecutor v. Ljube Boskoski y Johan Tarculovski, IT-04-82-T, Decisión del 10 Julio 2008. 
Generalmente, un conflicto armado entre un estado y un grupo armado organizado debería ser clasificado como un conflicto armado no internacional ${ }^{15}$. Hay dos excepciones a esta regla general, la primera es la situación en que el grupo armado organizado está de hecho vinculado al estado anfitrión y la segunda es cuando el estado defensor usa fuerza contra el grupo armado organizado en el territorio del estado anfitrión sin su consentimiento (véase arriba).

Los drones han sido utilizados en zonas donde no hay un conflicto activo. Esto se ha visto más públicamente en el uso de drones por los Estados Unidos ${ }^{16}$ que, particularmente bajo la administración de Bush, afirmaron que estaban involucrados en un conflicto armado no internacional sin confines territoriales contra 'al Qaeda y sus fuerzas asociadas'. Esto fue así expresado en un 'libro blanco' del Departamento de Justicia estadounidense: "cualquier operación estadounidense es parte de este conflicto armado no internacional, aunque ocurra lejos de la fuente de hostilidades activas" (Estados Unidos 'Department of Justice'). Con esta afirmación los Estados Unidos hicieron valer su derecho a aplicar el DIH a sus acciones contra al Qaeda y asociados, sin importar donde éstos se encuentren. La mayoría de comentadores jurídicos que han considerado el concepto estadounidense de 'guerra global contra el terror', concluyen que esta no es una interpretación legítima del concepto de conflicto armado no internacional. Sin duda la misma crea problemas cuando consideramos la aplicación del DIH. En primer lugar, hay que definir quién es un combatiente; consideraremos este punto en más detalle más adelante pero aquí vale la pena notar la pregunta planteada por Katja Schöberl ¿si no hay un campo de batalla definido, como puede un participante/combatiente salir del mismo? Otra, quizás más significativa problemática, es cmo determinar si el umbral de violencia ha sido cruzado para calificar la situación como conflicto armado. En su decisión de poner fin al procedimiento en el caso de los Asesinatos Selectivos en Pakistán, el Fiscal Federal Alemán afirmó que la determinación de la existencia de un conflicto armado será válida únicamente para un periodo de tiempo determinado y en un territorio definido (El Caso de Asesinatos Selectivos en Pakistan). Algunos comentadores opinan al contrario que la clasificación de un conflicto depende de las relaciones entre beligerantes, sin importar donde eéstos estén ubicados y por eso como el nexo territorial sea de poca o ninguna relevancia ${ }^{17}$. A este respecto citan el hecho que el $\mathrm{DIH}$ no intenta definir la geografía de un conflicto, sino solo las relaciones entre las partes. Se sugiere en este artículo que hay un elemento espacial en la intensidad de violencia que hay que considerar para determinar la existencia de un conflicto y su alcance territorial.

\section{Los principios de Jus in Bello y los drones}

En los conflictos armados internacionales el jus in bello no es afectado por jus ad bello, entonces, sin importar si un conflicto ha comenzado legalmente o no, los principios del jus in bello aplican.

Para determinar la legalidad de los usos de drones es necesario considerar los principios del DIH.

\section{Distinción y precaución}

El principio de distinción requiere que los civiles sean siempre distinguidos de los combatientes y participantes directos en el conflicto ${ }^{18}$. Esto presenta dos aspectos:

15 Véase el informe del New York City Bar en la página 107.

16 Otros estados, particularmente Israel y Reino Unido, han usado drones de una manera parecida. Véase www.middleeastmonitor. com/20160407-israeli-army-document-confirms-use-of-hermes-450-drones-in-assassinations/

17 Véase por ejemplo los artículos de Noam Lubbell.

18 Artículo 51, Protocolo Adicional I 
primero, significa que los civiles no pueden ser atacados (contrariamente a los participantes directos y combatientes); y segundo, requiere que los participantes directos y combatientes se distingan de la población civil.

Debemos definir quién es un participante directo en un conflicto. En conflictos armados internacionales los combatientes son los miembros de las fuerzas armadas de los estados en conflicto y por eso son fáciles de definir e identificar ${ }^{19}$. Pero, en conflictos armados no internacionales las partes son grupos armados organizados no estatales y muchas veces los miembros o participantes directos son difíciles de determinar, en consecuencia la definición de quién pueda ser atacado es más complicada. El articulo 51(3) del Protocolo Adicional I, excluye las personas que participan directamente en las hostilidades, mientras dure tal participación, de la protección que gozarán los civiles. El Comité Internacional de la Cruz Roja (CICR) ha intentado de ofrecer una guía en la interpretación del termino: 'participación directa en las hostilidades' (CICR, 2010). Esta identifica tres elementos necesarios antes de que una persona pueda ser considerada una participante directa en las hostilidades;

Umbral de daño: "Debe haber probabilidades de que el acto tenga efectos adversos sobre las operaciones militares o sobre la capacidad militar de una parte en un conflicto armado, o bien, o cause la muerte, heridas o destrucción a las personas o los bienes protegidas contra los ataques directos".

Causalidad directa: "Debe haber un vínculo causal directo entre el acto y el daño que puede resultar de ese acto o de la operación militar coordinada de la que el acto constituya parte integrante".

Nexo beligerante: "el propósito específico del acto debe ser causar directamente el umbral exigido de daño en apoyo de una parte en conflicto y en menoscabo de otra" (CICR, 2010).

Bajo esta definición, una persona solo puede ser atacada cuando participe directamente en las hostilidades cumpliendo con los elementos de arriba. Para responder a la crítica que esta definición es demasiado limitada especialmente en circunstancias donde miembros de grupos armados organizados frecuentemente actúan "como granjeros durante el día y como combatientes por la noche", el CICR ha formulado que hay miembros de grupos armados organizados que pueden tener funciones de combate continuas (CICR, 2010). Estos son individuos cuya función permanente consiste en la participación directa en las hostilidades y que, consecuentemente, pueden ser sujetas de ataque en cualquier momento.

Mientras estas definiciones pueden ser relativamente claras, incumbe a los estados interpretarlas de buena fe y basándose en hechos objetivos. Los Estados Unidos consideran que todos los miembros de un grupo armado organizado tienen una función de combate continúa, pero bajo la guía de la CICR solo los miembros cuya función permanente es la participación directa en las hostilidades cumplen con la definición (un miembro de un grupo armado organizado cuya función consiste en recaudar fondos o hacer propaganda no tiene una función de combate continua, mientras la posición de un fabricante de bombas es menos clara).

Otro asunto de debate cuando consideramos quien sea un participante directo en un conflicto, es el de 'co-beligerancia'. Es común en un conflicto armado no inter- 
nacional que un estado no luche contra un solo grupo armado organizado sino una plétora de grupos no estrechamente vinculados que pueden o no compartir algunos o todos de los objetivos.

Siguiendo a Heyns, cada grupo debería cruzar el umbral con respecto a la intensidad de violencia para ser considerado como una parte en el conflicto (Heyns, 2013). Meramente ser un afiliado o asociado de una parte en conflicto no significa automáticamente que el grupo armado organizado sea en sí mismo una parte en conflicto. La sola excepción a esto es cuando los grupos compartan las mismas estructuras de comando y control. Entonces, cuando se aplica el concepto de 'función de combate continuo', esa función tiene que ser como parte de un grupo armado organizado que sea parte en el conflicto ${ }^{20}$. Este aspecto es de particular relevancia para la situación colombiana cuando, como veremos a continuación, el estado está en el proceso de reclasificación de las partes en el conflicto armado.

Los que participan directamente en las hostilidades (por la duración de su participación) y aquellos con estatus de 'combatientes continuos', pueden ser sujetos de ataques, pero tienen que ser distinguidos de la población civil. Si hay dudas sobre el estatus de alguien la asunción debe ser que es un civil. En cualquier ataque, el DIH requiere de, "tomar todas las precauciones factibles en la elección de los medios y métodos de ataque para evitar o, al menos, reducir todo lo posible el número de muertos y de heridos que pudieran causar incidentalmente entre la población civil, así como los daños a los bienes de carácter civil" (Artículo 57 numeral 2 del Protocolo Adicional I).

Los proponentes de drones abogan que, con respecto a distinción y precaución, los drones ofrecen una cantidad de ventajas sobre los armamentos tradicionales. En primer lugar, a diferencia de aeronaves tripuladas, los drones pueden permanecer sobre sus objetivos durante largos periodos de tiempo. Esto permite a los operadores llevar a cabo una vigilancia detallada del sospechoso para establecer si es un sujeto de ataque o no y para tomar precauciones y evitar daños incidentales. Se entiende que los Estados Unidos en sus usos de drones requieren una evaluación de 'modo de vida' de 24 horas, antes de desplegar armamentos y abortan un ataque cuando haya un riesgo de más del 10 por ciento de daño incidental (Colon, 2015). Ataques pueden ser terminados a corto plazo si las circunstancias cambian (por ejemplo, si resulta evidente que hay civiles presentes).

En su artículo, "Drones and Distinction: How IHL Encouraged the Rise of Drones" Michael W. Lewis y Emily Crawford sugieren que la popularidad de los drones tiene poco que ver con la protección de fuerzas armadas estatales y afirman que en las zonas donde los drones están siendo usados frecuentemente, como Yemen y Afganistán, habría poco riesgo para un piloto de combate, pero los drones son preferidos a las medidas tradicionales porque son más precisos y ofrecen una mejor vigilancia. Estas características pueden ser particularmente útiles en situaciones donde los participantes se esconden entre la población civil, una práctica que Lewis y Crawford notan es "ilegítima pero, sin embargo, legalmente efectiva".

En cambio, hay numerosos informes que destacan los problemas del uso de drones y las dificultades en lograr una identificación fiable de individuos y de dirigir ataques contra éstos, particularmente en circunstancias donde el estado atacante no tiene una presencia en el territorio y consecuentemente es más dependiente de la 20 No obstante si un grupo no es considerado un parte al conflicto sus miembros pueden hacer actos vinculados al conflicto, eso sea considerado participación directa en hostilidades pero no dar lugar al estatus de combatiente continuo. 
inteligencia. Los Estados Unidos utilizan tres formas de inteligencia en sus operaciones con drones: grabación, inteligencia de señales (es decir inteligencia obtenida a través de la intercepción de telecomunicaciones) e inteligencia humana. En zonas remotas donde no se hace uso del internet la inteligencia de señales tiene un valor limitado (se pueden rastrear celulares y analizar los datos de llamadas pero en realidad los celulares cambian de manos frecuentemente y usuarios sofisticados usan tomar pasos para evitar de revelar información a través de sus celulares). Esto puede dejar a los operadores dependientes de grabación e inteligencia humana.

El análisis de la inteligencia humana puede ser difícil, especialmente cuando el estado atacante no tenga una presencia sobre el territorio. La inteligencia humana es notoriamente poco fiable, y la información puede ser manipulada, particularmente por informadores que pueden tener sus propias motivaciones para dar información falsa (venganza, recompensa financiación etc.) ${ }^{21}$. Los Estados no deberían confiar solamente en inteligencia humana sin corroboración.

Generalmente, la calidad de grabación es buena, pero los drones operan a gran altitud (típicamente 20-25.000 pies) y en lugares de población densa o con abundante vegetación la capacidad de identificar individuos puede ser limitada (Wheeler, 2012). No importa cuan avanzada sea la tecnología, los drones son operados por humanos y la capacidad de distinguir entre civiles y objetivos militares y de tomar precauciones para evitar víctimas civiles depende de la competencia de sus operadores.

Hay quienes manifiestan preocupaciones de que los operadores puedan tener o desarrollar una mentalidad de 'Playstation' y, con operadores tan lejos del campo de batalla, éstos puedan sentirse inmunes a las consecuencias de sus acciones (por otro lado, su situación segura les permitiría tomar mejores decisiones). No hay datos suficientes y quizás es demasiado temprano, en tema de uso de drones, para analizar efectivamente estas preocupaciones. Ciertamente, es importante que los operadores reciban un entrenamiento en $\mathrm{DIH}$, aunque sean civiles, como la CIA.

En febrero de 2010 los Estados Unidos mataron a 23 civiles en un ataque con drones en Afganistán. La investigación subsecuente descubrió que los civiles se habían identificado como combatientes por error, porque el operador del dron tenía 'data overload'. Esencialmente, estaba bajo presión y recibiendo tanta información que perdió las imágenes que demostraban claramente que el grupo consistía en civiles (incluyendo niños) (Shanker \& Ritchell, 2011). Estos son problemas nuevos e intrínsecamente vinculados al uso de estos tipos de tecnologías en combate; cualquier estado que implemente un nuevo programa de uso de drones debería, en la medida de lo posible, tomar pasos para evitar estos potenciales problemas.

El segundo aspecto, lo de la distinción, es el requisito de que los combatientes y participantes en un conflicto se distingan de la población civil $^{22}$. Hay preocupaciones sobre si los operadores de drones cumplan con este requisito, particularmente cuando son civiles, por ejemplo en el caso de la CIA. Cuando los drones son operados por civiles, es casi cierto que estos están participando directamente en las hostilidades (y muy probablemente podrían ser considerados tener una función de combate continuo). Por lo tanto, el centro de control y los operadores pueden ser objetivos militares legítimos bajo el DIH y deberían distinguirse de la población civil. El mero

21 Para un discurso interesante sobre este asunto véase el podcast de Malcolm Gladwell, "Saigon 1965" disponible en http:// revisionisthistory.com/episodes/02-saigon-1965

22 A este respecto se aplica a los drones su misma regulación 1, Manual on International Law Applicable to Air and Missile Warfare 
hecho que los drones sean operados desde lejos del sitio de despegue no viola por sí mismo el principio de distinción (El Caso de Asesinatos Selectivos en Pakistan).

En resumen, al menos con respecto al requisito de la distinción, no hay nada para sugerir que los drones per se violen este principio de DIH pero, como con cualquier otro armamento, es importante que sean usados de una manera que sea compatible con el DIH.

\section{Proporcionalidad}

El principio de proporcionalidad prohíbe ataques indiscriminados, específicamente los con probabilidad de causar un daño incidental que sea excesivo en relación con la ventaja militar concreta y directa anticipada (Artículo 51, numeral 5 del Protocolo Adicional I). Anteriormente hemos discutido algunas de las razones que los proponentes de los drones citan para afirmar que estos son más discriminatorios que los armamentos tradicionales. En este contexto vale la pena notar que los drones tienen la capacidad de desplegar municiones más ligeras que las desplegadas por aeronaves de combate tradicionales y hay evidencia que la dispersión de metralla es inferior (Byman, 2013). En teoría todo esto debería hacer de los drones armamentos más precisos.

En el otro lado del debate, algunos se preguntan si el uso de drones afuera del campo de batalla afecta la determinación de proporcionalidad. Existen pruebas crecientes sobre el daño psicológico causado a los residentes en zonas frecuentemente afectadas por ataques con drones (Center for Civilians in Conflict) (The Atlantic). Pero, en la ausencia de evidencia que el daño psicológico causado por drones a los que viven afuera de zonas de conflictos tradicionales es significativamente más alto que lo causado a los que viven en zonas de conflictos, se sugiere que el solo hecho que un ataque con dron sea conducido afuera el campo de batalla no debería afectar la determinación de proporcionalidad en jus in bello. Dicho esto, el hecho que el objetivo sea tan lejos del campo de batalla puede afectar su importancia como objetivo militar y consecuentemente la ventaja militar concreta anticipada (y esto es vinculado intrínsecamente con la proporcionalidad en jus ad bello discutida anteriormente).

Los drones ofrecen una opción binaria ¿de matar o no matar? En ausencia de tropas de tierra no hay posibilidad de rendirse (particularmente cuando los drones son usados de manera encubierta y el objetivo no es consciente del ataque) o de captura. La pregunta si el DIH crea una obligación de capturar en lugar de matar cuando sea posible es área de controversia. El CICR sostiene que tal obligación existe y que el grado y alcance de fuerza utilizada no debería pasar lo que es necesario para obtener el objetivo militar perseguido; pero otros comentaristas observan que no hay una tal obligación expresamente estipulada en ninguno de los Convenios.

El New York Bar Council, en su informe concluye que el principio de proporcionalidad (o necesidad) no requiere que las fuerzas militares tomen riesgos adicionales para capturar en lugar de matar (New York City Bar Committee on International Law, 2014) (Public Committee Against Torture in Israel v. Government of Israel, 2006). Mientras que eso es correcto, necesitamos preguntar si ¿los drones son usados para obviar riesgos o simplemente porque son más eficientes (como proponen Lewis y Crawford)? Es improbable que la eficiencia pueda ser un motivo válido para matar cuando capturar no implique riesgos adicionales. En el informe del CICR, Guía Para Interpretar la Noción de Participación Directa en Hostilidades Según el Derecho Internacional Humanitario, se afirma, con respecto a los principios de necesidad y 
humanidad: "La importancia práctica de la función de restricción de esos principios aumentará proporcionalmente a la capacidad de una parte en conflicto de controlar las circunstancias y el área en que lleva a cabo sus operaciones militares, y puede incluso ser decisiva cuando las fuerzas armadas operan contra ciertas personas en situaciones comparables a las de mantenimiento del orden en tiempo de paz" ( $\underline{\mathrm{CICR}}$, $2010)^{23}$

El hecho que los drones solo ofrezcan una opción binaria (matar o no matar) por sí mismo no los hace armamentos ilegales, pero va a afectar la decisión sobre cuando sea necesario usarlos. Si sea legítimo desplegar drones en una zona remota donde capturar no es viable, depende últimamente del valor del objetivo militar.

\section{Orden Público}

Drones no armados ya son usados ampliamente por agencias policiales, más que todo con función de vigilancia. Esto crea una serie de cuestiones, particularmente en relación con la privacidad y libertad de asociación, que no serán analizadas en este artículo. Lo mismo puede decirse en mérito al tema de drones que tienen capacidad de desplegar una fuerza que no sea letal.

Dejando a un lado los argumentos sobre la limitación territorial de la aplicación de los derechos humanos, cualquier uso de fuerza letal afuera de un conflicto armado o legítima defensa bajo el artículo 51, se rige por el derecho relevante interno y el derecho internacional de los derechos humanos ${ }^{24}$. El derecho a la vida está consagrado en varios instrumentos de DIDH y es considerado un derecho internacional consuetudinario ${ }^{25}$; pero, no es un derecho sin reservas. El Pacto Internacional de Derechos Civiles y Políticos, el Pacto de San José y la Carta Africana de Derechos Humanos y de los Pueblos, dicen que nadie podrá ser privado de la vida arbitrariamente. El Convenio Europeo de Derechos Humanos detalla estas reservas como sigue;

La muerte no se considerará como infligida en infracción del presente artículo cuando se produzca como consecuencia de un recurso a la fuerza que sea absolutamente necesario:

1. en defensa de una persona contra una agresión ilegítima;

2. para detener a una persona conforme a derecho o para impedir la evasión de un preso o detenido legalmente;

3. para reprimir, de acuerdo con la ley, una revuelta o insurrección

Lo que puede derivarse de estos tratados y de la jurisprudencia de las cortes internacionales es que, bajo el DIDH, el uso de fuerza letal tiene que ser necesario, proporcionado y regulado por normas jurídicas internas.

En este contexto, 'necesario' significa que el uso de fuerza letal debe ser el último recurso (ultima ratio). El requisito de última ratio, en la mayoría de circunstancias, significa que las autoridades deben aplicar una gradación en el uso de la fuerza, empezando con advertencias, seguidas por fuerza menor y solo últimamente por el uso de fuerza letal (es decir, sin matar cuando sea posible capturar). Por supuesto, hay situaciones excepcionales en las cuales será necesario usar fuerza letal sin primero tratar de usar medidas no letales ${ }^{26}$.

24 Solo una minoría de estados contestan que no son vinculados al DIDH afuera de sus territorios.

25 Artículo 4, Convención Americana Sobre Derechos Humanos; artículo 2, Convenio Europeo de Derechos Humanos; artículo 6. Pacto Internacional de Derechos Civiles y Políticos

26 Principio 10, Principios Básicos sobre el Empleo de la Fuerza y de Armas de Fuego por los Funcionarios Encargados de Hacer 
Para que el uso de fuerza sea proporcional, tiene que ser usada para proteger la vida (o por lo menos contra un perjuicio grave a la misma). Por lo tanto, si fuerza letal es usada para impedir una evasión, el preso debe presentar un riesgo real de causar al menos un daño físico que sea grave ${ }^{27}$. A diferencia del DIH, las reglas del DIDH sobre el uso de fuerza letal no permiten un daño incidental. Si hay un riesgo que otras personas puedan ser heridas gravemente en el ejercicio de fuerza letal es muy improbable que el uso de tal fuerza sea considerado proporcional.

El último requisito es que haya un marco legal interno que rija las situaciones en las cuales fuerzas estatales puedan usar fuerza letal para mantener el orden público. Derivado de éste, la jurisprudencia, particularmente de la Corte Europea de los Derechos Humanos, ha desarrollado una doctrina de precaución en la consideración del uso de fuerza letal planificada. Esencialmente, esta requiere que, en la planificación y organización de operaciones, todos los pasos posibles para prevenir el uso de fuerza letal sean adoptados ${ }^{28}$.

Las cortes también han destacado la necesidad de rendición de cuentas e investigación adecuada después de los hechos.

Si aplicamos estos principios al uso potencial de drones en situaciones de mantenimiento de orden público, la primera cosa a notar es que hasta ahora, mientras hay drones con la capacidad de desplegar una fuerza que no sea letal, tales como pistolas paralizantes y bolas de pintura para marcar sospechosos, la capacidad de drones de dar advertencias y desplegar fuerza graduada es ciertamente limitada. Esto por sí mismo limita enormemente las situaciones en las cuales el uso de drones armados para mantener el orden público pueda ser contemplado. Un dron armado solo podría usar fuerza letal en situaciones donde con el uso de otras tácticas, "se pusiera indebidamente en peligro a los funcionarios encargados de hacer cumplir la ley, se creara un riesgo de muerte o daños graves a otras personas, o resultara evidentemente inadecuada o inútil dadas las circunstancias del caso" (McCann and others v. united Kingdom, 1995).

En el DIDH podrá ser legítimo dirigir el objetivo contra alguien solo para el riesgo inminente que esté presente personalmente; no hay un equivalente a la función de combate continua que se encuentra en el DIH y fuerza letal extrajudicial nunca puede ser usada para actos pasados (fuerza letal como retribución).

En síntesis, hay pocas situaciones en las cuales drones armados puedan ser usados para mantener el orden público de una manera que cumpla con el DIDH. No obstante, en julio de 2016 la policía de Dallas, Estados Unidos, ha usado un robot para matar un sospechoso en un tiroteo masivo; esto se puede ver como análogo al uso de un dron armado y, solo porque es posible que no cumplan con el DIDH no necesariamente significa que los estados no vayan a usarlos (Thielman, 2016). Cualquier avance en el uso de drones armados por la policía o agencias similares podría ser considerado un paso significativo hacia la militarización de las fuerzas policiales.

\section{La situación Colombiana}

El hecho que Colombia tenga un territorio tan grande, con partes inaccesibles debido a su geografía (particularmente las zonas de selva) o a la ausencia de infraestructuras, significa que la movilidad aérea es crucial para las fuerzas armadas para lograr 
un control territorial. La importancia atribuida a los recursos aéreos ya había sido destacada en un informe de la embajada estadounidense a la CIA en 2008 donde se afirmaba que: "[la] diferencia más grande en el equilibrio de poder en el campo de batalla entre las fuerzas armadas colombianas y la Farc y otros grupos armados es en la movilidad aérea" (Public Library of US Diplomacy, 2008).

Sabemos que drones de vigilancia no armados, ScanEagle, se han utilizado en Colombia desde 2006, como parte de operaciones militares conjuntas entre Colombia y Estados Unidos contra narcotraficantes y grupos armados organizados y parece que las autoridades colombianas se han comprometido a la expansión de sus recursos de drones. En 2012 se anunció que Colombia había acordado un contrato por un valor de \$USD 10 millones con la empresa israelí Global CST, que incluía el suministro de drones Hermes 450 y 900 (Gil, 2014) (The Global Intelligence Files) y en 2013 que había pedido un Hermes 900 de la misma empresa israelí. No hay reportes de militares colombianos que hayan usado drones armados pero, mientras que ambos, el Hermes 450 y 900 son principalmente usados para vigilancia y misiones de reconocimiento, pueden ser adaptados para llevar armamentos y se cree que fueron usados por Israel en asesinatos selectivos (Middle East Monitor, 2016).

Mientras quedan algunas dudas sobre si Colombia tenga acceso a drones armados, es cierto que sus operaciones con drones (armados y no armados) ya son muy desarrolladas. En 2015 la Fuerzas Aérea Colombianas (FAC) anunció haber inaugurado su primer simulador de vuelo para entrenar los operadores de drones, que en futuro deberían servir "para simular todo tipo de escenarios y apoyar la toma de decisiones"29. Un artículo en la revista Semana informa sobre el carácter sofisticado y extensivo de operaciones con drones ya conducidas en el país, ambos en el contexto del conflicto armado y lucha contra el crimen organizado así como operaciones para la protección del medioambiente ${ }^{30}$.

Ha sido reportado que con la reducción en el uso de drones en el Medio Oriente por los Estados Unidos, sus drones serán redistribuidos en Asia y en la región del Pacífico. Colombia en particular, ha sido citada como un potencial nuevo anfitrión para drones estadunidenses que no serán necesarios en otros lugares (Whitlock, 2013).

Para decidir si la inversión en drones armados o su uso en combate valgan la pena, el gobierno colombiano tendría que analizar si éstos ofrecen ventajas significativas sobre los armamentos tradicionales que ya sean disponibles. Colombia ya tiene armamentos de precisión. En su artículo, 'Covert Action in Colombia', el Washington Post describió como, siguiendo el secuestro de cuatro contratistas estadounidense por la Farc en febrero de 2003, las fuerzas estadounidenses (incluyendo la CIA) colaboraron con las fuerzas militares colombianas en sus operaciones encubiertas contra la Farc (Priest, 2013) ${ }^{31}$. Inicialmente las operaciones se centraron sobre la inteligencia y a través de varias interceptaciones y con la ayuda de informadores las autoridades estadounidenses y colombianas fueron exitosas en ubicar los líderes de la FARC, pero a pesar de esto, en 2006 habían mostrado pocos progresos en la captura o muerte de los mismos. Entonces las fuerzas aliadas identificaron que sus tácticas (helicópteros que aterrizaban tropas terrestres para que se dirigieran hasta los campamentos) eran inefectivas y empezaron a buscar alternativas. La mejor opción que encontraron fueron los armamentos de precisión o 'smart bombs'.

29 http://www.fac.mil.co/colombia-inaugura-primer-simulador-de-avi\%C3\%B3n-remotamente-tripulad

30 Disponible en http://www.fac.mil.co/los-drones-se-unen-las-filas-de-la-fuerza-a\%C3\%A9rea

31 Estas operaciones recibieron financiamiento distinto a lo para el 'Plan Colombia' y fueron conducidas de manera encubierta, a diferencia del 'Plan Colombia'. 
Las 'smart bombs' pueden ser lanzadas de una aeronave que vuela a 20,000 pies. Están programadas con las coordenadas de GPS de sus objetivos y pueden ser lanzadas cuando estén a menos de tres kilómetros de dichos objetivos. Las fuerzas estadounidenses-colombianas empezaron a atacar a las Farc usando esta 'nueva' tecnología, que es relativamente económica y precisa. Las bombas eran fabricadas en los Estados Unidos, lanzadas de aeronaves colombianas y programadas por la $\mathrm{CIA}^{32}$. La acción resultó efectiva y se le atribuye el mérito de haber considerablemente debilitado el liderazgo de las Farc.

Además de las 'smart bombs' Colombia también tiene ahora misiles guiados por láser Griffin; éstos son similares a las 'smart bombs' en el sentido que pueden seguir una trayectoria para centrar un objetivo dentro un rango de precisión de cinco metros.

La limitación con ambos tipos de estos armamentos es que funcionan con municiones relativamente pesadas (por lo menos bombas de 500 libras) y su duración de vuelo es considerablemente menor que la de los drones. El dron Hermes 900 tiene una duración de vuelo de hasta 36 horas y los drones en general tienen capacidad de operar con municiones mucho más ligeras, lo cual aumenta la precisión (haciéndolos particularmente adecuados para operaciones de asesinato selectivo como descrito arriba). Es posible que la precisión no sea elemento particularmente importante en la selva pero, si el objetivo está en una zona más poblada, puede representar una ventaja significativa. En muchos aspectos, es probable que el uso de drones armados en Colombia vaya a depender de las tácticas adoptadas y el nivel de amenaza planteado por los grupos armados, nuevos o establecidos. Si el gobierno adopta un enfoque a largo plazo puede considerar que, mientras que la inversión inicial en la adquisición de drones y en el entrenamiento de los operadores es significante, en seguida los gastos de funcionamiento son muy reducidos y los drones podrían ser los armamentos más efectivos.

Será necesario tener en cuenta el marco legal dentro del cual los drones podrán ser desplegados en Colombia. Si los drones se utilizan por las fuerzas armadas colombianas el marco legal será lo mismo que lo aplicable a las 'smart bombs' o a cualquier otro armamento. Desde al menos 2007 se reconoce por lo general que la situación en Colombia equivale a un conflicto armado no internacional al que se aplican tanto el artículo 3 común de los cuatro Convenios de Ginebra como el Protocolo Adicional $\|^{33}$. Sujeto a los principios de distinción, precaución y proporcionalidad, las fuerzas armadas pueden atacar legítimamente personas que participen directamente en las hostilidades y miembros de grupos organizados armados que tengan una 'función de combate continuo', siempre cuando el grupo armado sea una parte del conflicto.

La situación en Colombia está marcada por una proliferación de grupos armados con motivos tanto políticos como no políticos. En la determinación de quien sea una parte en el conflicto el estado distingue entre grupos armados organizados (GAO) y grupos delictivos organizados (GDO). La Directiva Ministerial Permanente 014 de 2011 ha clasificado muchos de estos grupos, incluidos los desmovilizados grupos paramilitares y los narcotraficantes, como bandas criminales (BACRIM), de esta manera confirmando que los mismos deben ser abordados en el marco del mantenimiento del orden público (DIDH).

32 El Washington Post reporta que inicialmente las autoridades estadounidenses no confiaban en los militares colombianos con los códigos para programar el GPS debido a que esto podía ser usado contra oponentes políticos. Desde 2010 los militares colombianos han tenido control sobre el proceso completo.

33C-225 de 1995 y Directiva Permanente 10 de 2007 
La Directiva Permanente 15 de 2016 ha suplantado la Directiva Ministerial Permanente 014 de 2011. Algunos grupos que bajo la 14/2011 se consideraban como BACRIM (o grupos delictivos organizados), bajo la 15/2016 son considerados como GAO (grupos armados organizados). La Directiva Permanente 15 de 2016 descarta cualquier requisito de motivación o estatus político por estos grupos. Grupos armados organizados son definidos como: "los que bajo la dirección de un mando responsable ejerzan sobre una parte del territorio un control tal que les permita realizar operaciones militares sostenidas y concertadas". Bajo la Directiva hay tres elementos para satisfacer esta definición;

El uso de violencia armada contra las fuerzas estatales o instituciones estatales o contra población civil, bienes civiles u otros grupos armados;

Que el grupo tenga la capacidad de generar un nivel de violencia armada que supere la de los disturbios o tensiones internas (i.e. el umbral de violencia);

Que el grupo tenga un nivel de organización y liderazgo que permita la realización de las operaciones violentas mencionadas en i. y ii².

El Centro Integrado de Inteligencia Contra los Grupos Delictivos Organizados y Grupos Armados Organizados (C12-GDO/GAO) tendrá responsabilidad para recoger y analizar la inteligencia sobre los grupos y presentará informes bimestrales al Acuerdo de Comandantes del Sector Defensa (el Acuerdo). Corresponderá al Acuerdo determinar, basado en la evidencia da C12-GDO/GA0, cuales grupos cumplan con los criterios para ser considerados GAO. A su vez el Acuerdo presentará sus conclusiones al Consejo de Seguridad que decidirá si ratificar la clasificación o no.

La Directiva Permanente 15 de 2016 así justifica su cambio de posición con respecto a las varias bandas criminales: "En los últimos años han surgido cambios significativos en el teatro de operaciones y en el comportamiento y agrupación de los actores que confluyen en él, pues se han evidenciado transformaciones del sistema criminal que actúa en algunos territorios". Pero no profundiza en esta afirmación. El momento en que se emitió la Directiva puede haber sido significativo: con las Farc debilitada considerablemente y esperanzas de un acuerdo por la paz, es posible que el gobierno se haya preocupado de que otros grupos armados puedan adquirir control sobre territorios anteriormente controlados por las Farc. Es también posible que se hayan tenido en mente los problemas de crimen organizado en otras partes de la región. Dependiendo de cómo será aplicada, la Directiva podría representar una amplificación significativa del 'conflicto' y un aumento en el uso de los poderes militares en lugar de la policía para combatir el crimen organizado.

La Directiva refleja y cumple con la definición de grupos armados organizados que puede derivarse del DIH pero mucho dependerá de cómo la definición sea interpretada por las autoridades. La Directiva crea un proceso con varios pasos para la aprobación de decisiones por diferentes cuerpos estatales, pero no hay provisión para hacer públicos los informes ni para un control judicial en el proceso. Es discutible si el nivel de medidas para asegurar la necesaria rendición de cuentas sea adecuado, dadas las enormes consecuencias de las decisiones. No hay ninguna explicación de cómo aplicar las nociones de participación directa en hostilidades ni de función de combate continuo a grupos tradicionalmente considerados bandas criminales. Todo esto puede ser particularmente problemático con respecto a grupos cuyas funciones principales van a estar relacionadas con el crimen organizado y no con el combate.

En las circunstancias actuales, es difícil imaginar que Colombia pueda ser parte de 
un conflicto armado internacional. Ciertamente hay un riesgo que el conflicto armado interno pueda desbordarse sobre las fronteras nacionales, particularmente si los GAO se basan en países vecinos. Hay un precedente para esto: en 2008 Colombia ha usado 'smart bombs' para atacar un campamento de las Farc, donde estaba Raúl Reyes, situado cerca de la frontera en territorio ecuatoriano, en una operación llamada 'Operación Phoenix'. Las bombas se lanzaron de aviones que permanecieron en el espacio aéreo colombiano y después del bombardeo tropas terrestres entraron en el campamento. La operación resultó exitosa en matar Raul Reyes (y otros) pero causó una crisis diplomática entre Colombia por un lado y Ecuador y Venezuela por otro. Inicialmente Colombia trató de justificar sus acciones usando la doctrina de la 'persecución en caliente', pero esta defensa fue desacreditada rápidamente. Ahora sabemos mucho más sobre lo que pasó en la Operación Fenix y es claro que Colombia atacó el campamento en pleno conocimiento de que éste estaba ubicado en territorio ecuatoriano. Las fuerzas estadounidenses eran conscientes del ataque (la CIA tuvo que programar las 'smart bombs') y consideraron que podía justificarse como legítima defensa, aplicando el mismo rasero a la operación que a sus ataques con drones en Medio Oriente (es decir su interpretación de legítima defensa en la que la inminencia no es necesariamente temporal). La intervención de los Estados Unidos en el conflicto colombiano fue consensual (Priest, 2013).

Sigue siendo posible que grupos armados busquen refugio en países vecinos, particularmente Venezuela y Ecuador. El hecho de que ambos países juzgarían con dureza acciones militares sin consenso (particularmente improbable en el caso de Venezuela) en sus territorios, debería ser un factor político disuasivo para llevar a cabo dichas acciones. Las ramificaciones políticas de un ataque con un dron sin consenso en Ecuador o Venezuela tienen potencial para ser considerablemente más graves que las que se plantean a los Estados Unidos cuando llevan a cabo ataques desde miles de millas contra países menos poderosos en el Medio Oriente.

El cambio de énfasis en el conflicto colombiano hacia bandas criminales puede presentar un mayor riesgo que el conflicto vaya a cruzar las fronteras territoriales: es probable que las bandas criminales involucradas en tráficos ilícitos tengan asociados internacionales o posiblemente una presencia internacional particularmente sobre las rutas comerciales. Sin embargo es posible que las autoridades Colombianas lleguen a acuerdos con algunos de estos países para combatir juntos el crimen organizado (ya hay algunos acuerdos en existencia ${ }^{34}$ ); pero queda por ver si esos acuerdos se podrían extender a clasificar las operaciones contra estos grupos como parte de un conflicto armado.

\section{Conclusión}

Los drones armados no son ilegales per se; son los usos que se hacen de los drones armados que plantean retos legales y morales. Muchos de estos retos no son únicos a los drones armados sino la proliferación de los usos de drones ha destacado asuntos de DIH que carecen de claridad en el panorama de conflictos modernos. Los dos asuntos más críticos en este respecto son los parámetros de la doctrina de legítima defensa en derecho internacional y la distinción entre bandas criminales en situaciones de violencia criminal y grupos armados organizados en conflictos armados.

La doctrina de legítima defensa en derecho internacional puede parecer de poca importancia para la situación colombiana pero, como hemos visto en la Operación Feenix, tiene potencial para ser relevante. Los drones tienen la capacidad de cruzar 
fronteras de manera encubierta y de usar fuerza letal contra individuos específicos. Precisamente estas dos características, ocultación y precisión, han permitido el uso de drones en territorios extranjeros sin que el estado operador haya debido enfrentar las consecuencias prácticas, políticas ni legales que hubiera planteado el uso de armamentos tradicionales. Estados poderosos han podido afirmar la legítima defensa para justificar sus acciones y, mientras la aplicación de la doctrina puede ser criticada, todavía se enfrentan pocas o ningunas consecuencias.

Cuando miramos al uso de drones por parte de los Estados Unidos y otros países, el asunto de cómo distinguir entre actividades delictivas y actividades que son parte de un conflicto armado, se vuelve fundamental. Históricamente los estados han sido reluctantes a reconocer conflictos armados no internacionales, y han mantenido que solo se trataba de una amenaza 'terrorista', manejada dentro el marco del DIDH. Esto puede haber sido para evitar de mostrarse débil o inestable o para evitar de conferir una percepción de legitimidad al grupo armado. Hoy en día vemos lo contrario, parece que los estados están dispuestos a explotar lo que Profesor Philip Alson describió como el "sumamente problemático oscurecerse... de los límites de los marcos legales aplicables", el resultado del cual, "ha sido el desplazamiento de claros estándares legales y una licencia a matar vagamente definida" (Alston, 2010). Vemos esto en el uso de drones en Medio Oriente, pero se puede argumentar que también se demuestra en la Directiva Permanente 15 de 2016. Hay pocas dudas que altos niveles de crimen violento y organizado pueden justificar la clasificación de una situación como un conflicto armado pero la dificultad es en la determinación de donde trazar la línea entre las dos ${ }^{35}$. Mientras hay incertidumbre está abierto a los estados para explotar la ausencia de una distinción clara con el fin de usar el régimen más permisivo del DIH. Esto permite a los estados (y en las circunstancias actuales el riesgo es real) de adoptar medidas más draconianas (particularmente el uso de fuerza letal que, dependiendo de las circunstancias, podría involucrar daño incidental) que no serían permitidas bajo el DIDH.

Cuando el derecho es incierto, normalmente corresponde a las cortes clarificar su interpretación, pero no hay ninguna jurisprudencia vinculante sobre el uso de drones. Hay varios casos donde cortes nacionales han considerado la legalidad de ataques con drones y cortes internacionales se han pronunciado sobre el uso de asesinatos selectivos en otros contextos, pero no hay una línea clara para guiar los estados en la determinación de la legitimidad de sus acciones. A medida que más estados adquieran acceso a drones armados y sus usos aumentan, la necesidad para un marco legal claro será más urgente.

\section{Referencias}

Abe, N. (14 Diciembre 2012). The Woes of an American Drone Operator. Spiegel Online.

Alston, P. (2010). Report of the Special Rapporteur on Extrajudicial, Summary or Arbitrary Executions. ONU , Asamblea General. New York: ONU. http://www2.ohchr.org/ english/bodies/hrcouncil/docs/14session/A.HRC.14.24.Add6.pdf

Anderson, K. (2011). Targeted Killing and Drone Warfare: How We Came to Debate

35 El 'Barómetro de Conflicto' producido por la Universidad de Heidelberg clasifica la situación en México como un conflicto del nivel mas grave. Disponible en https://www.hiik.de/en/ 
Whether There Is A 'Legal Geography Of War'. Washington College of Law. https:// papers.ssrn.com/sol3/papers.cfm?abstract id=1824783

Barela, S. J. (2015). The Question of 'Imminence': A Historical View on Anticipatory Attacks. En S. J. Barela (Ed.), Legitimacy and Drones, Investigating the Legality, Morality and Efficacy of UCAVs. Ashgate Publishing Ltd. https://www.routledge.com/ Legitimacy-and-Drones-Investigating-the-Legality-Morality-and-Efficacy/

Berger, S. (13 Agosto 2015). Mexico Drug Trafficking Drone Carries 28 Pounds of Heroin Across Border to US. International Business Times. http://www.ibtimes.com/mexico

Brumfield, E. (2014). Armed Drones for Law Enforcement: Why it Might be Time to Re-Examine the Current Use of Force Standard. Mc George Law Review, 46, 543. http://www.mcgeorge.edu/Documents/Publications/46304Brumfieldlssue3.pdf

Byman, D. (2013). Why Drones Work: The Case for Washington's Weapons of Choice. Foreign Affairs, 92, 32. https://www.brookings.edu/articles/why

Center for Civilians in Conflict. (s.f.). The Civilian Impact of Drones: Unexamined Costs, Unanswered Questions. Columbia Law School Human Rights Clinic, Center for Civilians in Conflict. http://civiliansinconflict.org/uploads/files/publications/The Civilian Impact of Drones w cover.pdf

Chatham House. (s.f.). Principles of International Law on the Use of Force in Self-Defence. London: Chatham House. https://www.chathamhouse.org/publications/papers/view/108106

CICR. (Marzo 2008). How is the Term Armed Conflict Defined in International Humanitarian Law. ICRC Opinion Paper. https://www.icrc.org/eng/resources/documents/ article/other/armed-conflict-article-170308.htm

CICR. (2010). Guía para Interpretar la Noción de Participación Directa en Hostilidades según el Derecho Internacional Humanitario. (N. Melzer, Ed.) https://www.icrc.org/ spa/assets/files/other/icrc 003 0990.pdf

Colon, C. R. (2015). Correcting the Record: Civilians, Proportionality, and Jus ad Vim. En S. J. Barela (Ed.), Legitimacy and Drones, Investigating the Legality, Morality and Efficacy of UCAVS. Fareham: Ashgate Publishing Ltd.

Crawford, Emily y Lewis, Michael W. (2013). Drones and Distinction: How IHL Encouraged the Rise of Drones. Georgetown Journal of International Law, 44, 1127-1166. https://www.law.georgetown.edu/academics/law-journals/gjil/recent/upload/ zsx00313001127.PDF

El Caso de Asesinatos Selectivos en Pakistan (Fiscalia General de la Republica Federal de Alemania).

Estados Unidos 'Department of Justice'. (s.f.). Lawfulness of a Lethal Operation Directed Against a U.S. Citizen Who Is a Senior Operational Leader of Al-Qa'ida or An Associated Force. https://fas.org/irp/eprint/doj-lethal.pdf

Friedersdorf, C. (25 Setiembre 2012). Every Person is Afraid of the Drones': The Stri- 
kes Effects on Life in Pakistan. The Atlantic. https://www.theatlantic.com/international/archive/2012/09/every-person-is-afraid-of-the-drones-the-strikes-effect-onlife-in-pakistan/262814/

Gasser, H.-P. (1993). International Humanitarian Law: An Introduction. En H. Haug (Ed.), Humanity for All: the International Red Cross and Red Crescent Movement (págs. 510-511). Berne: Paul Haupt. https://www.amazon.com/Humanity-all-International-Crescent-Movement/dp/3258047197

Gil, L. (9 Diciembre 2014). Global CST. El Tiempo. http://www.eltiempo.com/archivo/ documento/CMS

Gladwell, M. (s.f.). Saigon 1965. Obtenido de Revisionist History: http://revisionisthistory.com/episodes/02

Grzebyk, P. (2015). Who Can be Killed? Legal Targets in Non-International Armed Conflicts. En S. J. (ed), Legitimacy and Drones, Investigating the Legality, Morality and Efficacy of UCAVs. Farnham: Ashgate PublishingLtd. https://www.amazon.com/ Legitimacy-Drones-Investigating-Technologies-International/dp/1472446879

Heyns, C. (2013). Informe del Relator Especial sobre Ejecuciones Extrajudiciales, Sumarias o Arbitrarias. Asamblea General de la ONU. ONU. http://www.ohchr.org/SP/ Issues/Executions/Pages/SRExecutions/ndex.aspx

John Brennan, A. d. (11 de Setiembre de 2016). Strengthening Our Security by Adhering to Our Values and Laws. https://obamawhitehouse.archives.gov/the-pressoffice/2011/09/16/remarks

Koh, H. H. (14 Mayo 2013). How to End the Forever War. Yale Global Online. http:// yaleglobal.yale.edu/content/how

Kretzmer, D. (2013). The Inherent Right to Self-Defence and Proportionality in Jus ad Bellum. EJIL, 24(1), 235-282. https://oup.silverchair-cdn.com/oup/backfile/Content public/Journal/ejil/24/1/10.1093/ejil/chs087/2/chs087.pdf?

McCann and others v. United Kingdom, 18984/91 (European Court of Human Rights, 27 Setiembre 1995).

McNeal, G. S. (2012). Are Targeted Killings Unlawful? A Case Study in Empirical Claims Without Empirical Evidence. En J. D. Claire Finkelstein, Targeted Killing Law and Morality in an Asymmetrical World. Oxford: Oxford University Press. https://global.oup.com/academic/product/targeted

Middle East Monitor. (7 Abril 2016). Israeli Army Confirms Use of Hermes 450 Drones in Assassinations. Obtenido de https://www.middleeastmonitor.com/20160407

New York City Bar Committee on International Law. (2014). The Legality Under International Law of Targeted Killings by Drones Launched by the United States.

Nicaragua v. United States of America (International Court of Justice 1986). http:// scholarship.law.nd.edu/cgi/viewcontent.cgi?article=1070\&context=ndjicl

Nolte, G. (2004). Preventative Use of Force and Preventative Killings: Moves into a 
Different Legal Order. Theoretical Inquiries in Law, 5, 111. http://www7.tau.ac.il/ojs/ index.php/til/article/viewFile/486/450

Nolte, G. (2011). Targeted Killing. Max Planck Encyclopaedia of Public International Law . http://opil.ouplaw.com/view/10.1093/law

Opinión Consultiva de la Corte Internacional de Justicia sobre la Legalidad de la Amenaza o Empleo de Armas Nucleares (CIJ 1996).

Pejic, J. (Mayo 2015). Extraterritorial Targeting by Means of Armed Drones: Some Legal Implications. International Review of the Red Cross. https://www.icrc.org/en/ document/jelena

Poulain, N. y Groux, Natacha Farina. (2013). Synthesis on Drones. CICR.

Priest, D. (21 Diciembre 2013). Covert Action in Colombia. The Washington Post. http://www.washingtonpost.com/sf/investigative/2013/12/21/covert

Public Committee Against Torture in Israel v. Government of Israel, HCJ 769/02 (Supreme Court of Israel 13 Diciembre 2006).

Public Library of US Diplomacy. (30 Mayo 2008). Air Mobility Key to Success in Colombia. Obtenido de Wikileaks: www.wikileaks.org/plusd/cables/08BOGOTA1988 a.html

Shanker, T., \& Ritchell, M. (16 de Enero de 2011). In New Military, Data Overload Can be Deadly. New York Times. http://www.nytimes.com/2011/01/17/technology/17brain. $\underline{\text { html? pagewanted }=\text { all } \& r=0}$

Sharkey, N. (2012). Automated Warfare: Lessons Learned from Drones. Journal of Law, Information and Science, 8. http://www.austlii.edu.au/au/journals/JILaw/nfoSci/2012/8.html

Sharkey, N. (12 Julio 2016). Are We Prepared for More Killer Robots? The Guardian. Sifton, J. (7 Febrero 2012). A Brief History of Drones. The Nation. https://www.thenation.com/article/brief

Sims, A. (9 Julio 2016). The Consecuences of Global Armed Drone Proliferation. The Diplomat. http://thediplomat.com/2016/07/the

Szenat, F. y Bird, Annie (2012). Colombia. En E. Wilmhurst (Ed.), International Law and the Classification of Conflicts. Oxford University Press. https://global.oup.com/ academic/product/international

The Global Intelligence Files. (s.f.). Colombia Hostage Rescue: The Israeli Angle. Obtenido de Wikileaks: www.wikileaks.org/gifiles/docs

Thielman, S. (8 Julio 2016). Use of Police Robot to Kill Dallas Shooting Suspect Believed to be First in US History. The Guardian. https://www.theguardian.com/technology/2016/jul/08/police

Wheeler, W. (29 Febrero 2012). Finding the Right Targets. Time. http://nation.time. com/2012/02/29 
Whitlock, C. (20 Julio 2013). US Military Drone Surveillance is Expanding to Hot Spots

Beyond Declared Combat Zones. The Washington Post. https://www.washingtonpost. com/world/national-security/us-military-drone-surveillance-is-expanding-to-hot

Zenko, M. (5 Julio 2016). Do Not Believe the U.S. Government's Official Numbers on Drone Strike Civilian Casualties, It's Way Too Low. Foreign Policy. http://foreignpolicy. com/2016/07/05/do 